\title{
Outcomes of total versus subtotal abdominal hysterectomy
}

N. Asnafi, ${ }^{1}$ Z. Basirat ${ }^{7}$ and K.O. Hajian-Tilaki ${ }^{7}$

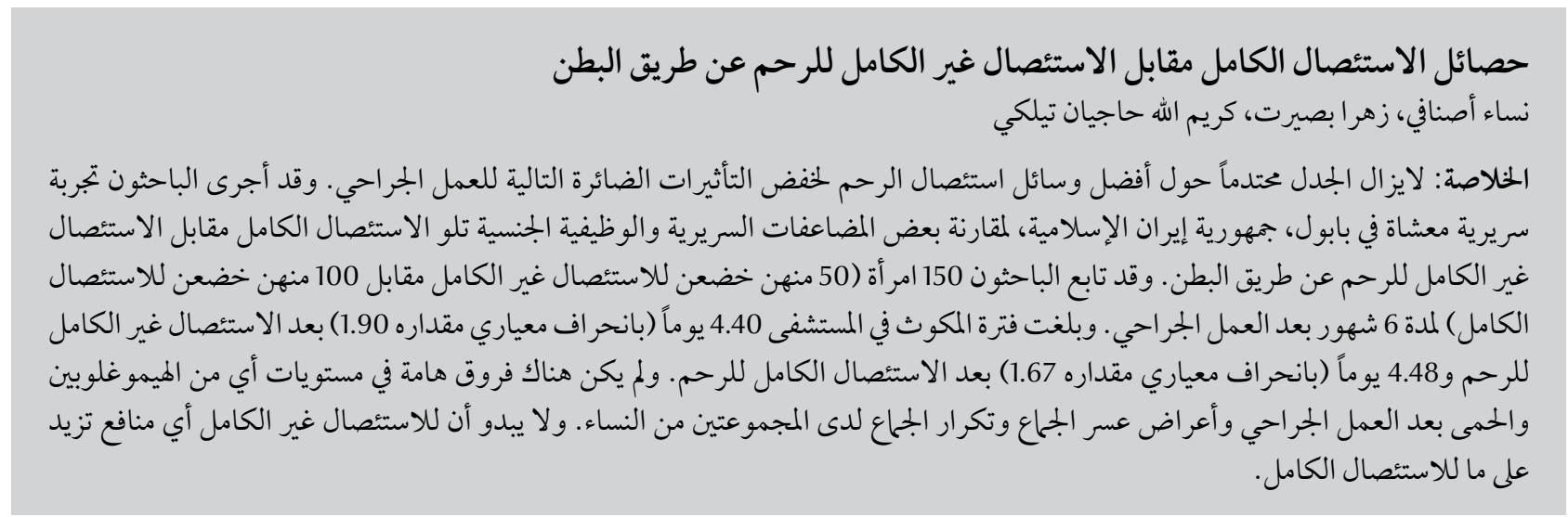

ABSTRACT There is still controversy about the best technique for hysterectomy to reduce postoperative adverse effects. This randomized clinical study in Babol, Islamic Republic of Iran, compared some clinical complications and sexual functioning following subtotal $(\mathrm{SAH})$ and total abdominal hysterectomy $(\mathrm{TAH})$. A total of 150 women (50 allocated to SAH and 100 to TAH) were followed up at 6 months postoperatively. Length of hospitalization was 4.40 (SD 1.90) days after SAH and 4.48 (SD 1.67) days after TAH. Haemoglobin level, postoperative fever, symptoms of dyspareunia and frequency of sexual intercourse were not significantly different between the 2 groups of women. SAH did not show any significant benefits over TAH.

\section{Comparaison des résultats de l'hystérectomie subtotale et de l'hystérectomie abdominale totale}

RÉSUMÉ Il existe toujours une controverse quant à la technique d'hystérectomie permettant le mieux de réduire les effets indésirables postopératoires. Une étude clinique randomisée réalisée à Babol, en République islamique d'Iran, a comparé les complications cliniques et la fonction sexuelle après une hystérectomie subtotale et une hystérectomie abdominale totale. Un groupe de 150 femmes (50 ayant subi la première et 100 la seconde) a été suivi pendant six mois après l'opération. La durée d'hospitalisation était de 4,40 jours (écart type 1,90) après une hystérectomie subtotale et de 4,48 jours (écart type 1,67) après une hystérectomie abdominale totale. Le taux d'hémoglobine, la fièvre postopératoire, les symptômes de dyspareunie et la fréquence des rapports sexuels ne présentaient pas de différence significative entre les deux groupes. L'hystérectomie subtotale n'a pas apporté d'avantage important par rapport à une hystérectomie abdominale totale. 


\section{Introduction}

Although hysterectomy is the most common gynaecologic operation $[1-4]$, the best technique for reducing adverse postoperative effects has not been clearly determined. Total abdominal hysterectomy (TAH) involves the removal of both the body of the uterus and the cervix whereas subtotal abdominal hysterectomy $(\mathrm{SAH})$ conserves the cervix [5].

Some authors believe that SAH minimizes anatomical disruption so it has fewer adverse effects than TAH (e.g. wound infection, haematoma and symptomatic vault granulation) $[6,7]$, while the risk of developing cervical cancer after SAH remains $<0.1 \%$ [8]. The most frequent complication after $\mathrm{TAH}$ [and cause of litigation in the United States of America (USA)] is injury to the urinary tract, which occurs in $0.5 \%-3.0 \%$ of cases $[9,10]$. The effect of different types of hysterectomy on sexual behaviour and dyspareunia is not fully understood [11-13]; it is believed that the uterus plays a role in the physiology of orgasm and many researchers have contended that total hysterectomy has an adverse effect in some women. Surgeons offer SAH as an option with less negative impact on sexual function [14]. Due to these inconclusive results, we performed this study in the Islamic Republic of Iran to compare the outcomes of SAH versus TAH regarding fever, anaemia, duration of hospitalization and changes in sexual function.

\section{Methods}

From January to December 2005, a randomized clinical study was conducted on 150 women at the Department of Gynaecology, Yahyanejad Teaching Hospital, Babol Medical University.

\section{Sample}

We estimated a sample size of 150 in order to detect a $20 \%$ difference between the groups with $80 \%$ statistical power at an alpha level of 0.95 and confidence level of $95 \%$.

We recruited all premenopausal women over 35 years who had been offered abdominal hysterectomy for $\geq 1$ of the following criteria: symptomatic uterine leiomyomata (bleeding, pain, discomfort) with sonographic confirmation of lesion or abnormal uterine bleeding without any response to hormone therapy of at least 3 months trial.

All patients had had structural evaluation of the endometrial cavity 6 months prior to enrolment (by ultrasound, hysteroscopy or endometrial biopsy) to exclude lesions amenable to hysteroscopic treatment $[1,2]$. They had also had an endometrial biopsy in the previous 6 months with a negative result for hyperplasia or carcinoma. Each woman had had a Papanicolaou smear showing no cellular changes suggestive of cervical dysplasia within 1 year prior to the study. Women aged 45-50 years enrolled in our study were confirmed as premenopausal if they had follicle stimulating hormone levels $\leq 30 \mathrm{mIU} / \mathrm{mL}$. Exclusion criteria were: age $>50$ years at screening; positive pregnancy test; genital tract carcinoma; body weight $>100 \mathrm{~kg}$; diabetes mellitus; candidates for vaginal hysterectomy determined by a gynaecologist; or unlikely to remain geographically accessible for follow-up. The final sample was 150 women; 11 women were excluded.

The women were randomly assigned to SAH (50 women) or TAH (100 women). The patients in both groups were distributed equally for surgery between 2 surgeons. Bilateral ovariectomy was performed only for patients over 45 years [1], and for these women $0.625-1.25 \mathrm{mg}$ conjugated oestrogen was prescribed daily with control of blood sugar, lipid profile and blood pressure.

\section{Data collection}

For each woman we recorded data about demographic characteristics and the preoperative gynaecological examination, the type of operation, postoperative hospital stay (including length of hospitalization, presence of postoperative pyrexia and haemoglobin). We measured body temperature by the oral method at 4-hour intervals after the operation until the patient was discharged. Pyrexia was defined as core body temperature $>38^{\circ} \mathrm{C}$ on $\geq 1$ occasion or $37.5^{\circ} \mathrm{C}$ on $\geq 2$ occasions 24 hours postoperation until discharge. Haemoglobin was measured on the first day after the operation: the cut-off for defining anaemia was $\mathrm{Hb}<10 \mathrm{~g} / \mathrm{dL}$.

Before the operation the women were asked if they had any pelvic or vaginal pain during sexual intercourse and 6 months postoperatively patients who had dyspareunia were asked about how the pain during intercourse had changed after the operation (increased, decreased or no change). Six months after the operation we also asked all patients who were sexually active before the operation about any changes in the frequency of sexual intercourse due to the operation (increased, decreased or no change).

Thelocalethics committee approved the study and all the patients gave their informed consent for participation.

\section{Analysis}

Quantitative variables were compared by $t$-test, and the outcomes of therapy in both groups were compared by the chi-squared and Fisher exact tests.

\section{Results}

The baseline characteristics of both groups are shown in Table 1.The mean age of the TAH group (100 cases) was 45.6 [standard deviation (SD) 6.5] years and for the SAH group (50 cases) was 43.3 (SD 7.0) years. A total of 26 women $(52.0 \%)$ in the SAH and 66 (66.0\%) in the TAH group also underwent bilateral salpingo-oopharectomy $(P=0.20)$. 


\begin{tabular}{|c|c|c|c|}
\hline Variable & $\begin{array}{c}\text { Subtotal } \\
\text { hysterectomy } \\
(n=50)\end{array}$ & $\begin{array}{l}\text { Total hysterectomy } \\
\qquad(n=100)\end{array}$ & $P$-value \\
\hline Mean (SD) age (years) & $43.3(7.0)$ & $45.6(6.5)$ & $0.51^{\mathrm{a}}$ \\
\hline $\begin{array}{l}\text { Mean }(\mathrm{SD}) \text { preoperative } \\
\text { haemoglobin }(\mathrm{g} / \mathrm{dL})\end{array}$ & $11.93(0.19)$ & $11.90(0.13)$ & $0.72^{\mathrm{a}}$ \\
\hline $\begin{array}{l}\text { No. (\%) with bilateral } \\
\text { oophorectomy }\end{array}$ & $26(52)$ & $66(66)$ & $0.20^{\mathrm{b}}$ \\
\hline
\end{tabular}

${ }^{a}$ t-test; ${ }^{b}$ Chi-squared and Fisher exact test. $S D=$ standard deviation .

The mean length of hospitalization for the SAH group was 4.40 (SD 1.90) days and for the TAH group was 4.48 (SD 1.67) days $(P=0.953)$.

Postoperatively, there was no significant difference in mean haemoglobin level between the 2 groups $(P=0.72)$ (Table2). Neither wasthere a difference in the proportion of women suffering postoperative pyrexia $(P=0.381)$. To assess dyspareunia, only those patients that complained of dyspareunia before the operation were studied (14 with $\mathrm{SAH}$ and 39 with TAH). The proportion who reported suffering increased dyspareunia 6 months postoperatively was $21.4 \%$ in the $\mathrm{SAH}$ and $41.0 \%$ in the TAH group; $57.2 \%$ and $28.3 \%$ respectively reported no change. However, these differences were not statistically significant $(P>0.05)($ Table 2).

The analysis of sexual activity was limited to the 48 women in the SAH group and the 89 women in the TAH group who were sexually active before the operation. Six months after the operation no change in the frequency of sexual intercourse was reported by $56.3 \%$ of the SAH and $55.1 \%$ of the TAH group and the difference was not significant $(P>0.05)$ (Table 2).

\section{Discussion}

Although a series of nonrandomized studies showed that SAH had some advantages over $\mathrm{TAH}$ with respect to urinary and sexual function [15-18], subsequent study has failed to confirm the results [19]. In our study, we found no significant differences between the 2 treatment groups in any of the measured parameters: postoperative pyrexia, length of hospitalization or haemoglobin level. These findings were similar to those reported by Lee et al., who noticed no differences in blood loss, febrile events, length of hospital stay and complications between TAH or SAH treated groups [20].

Regarding sexual function, we followed all patients for 6 months after the operation and found no significant differences in self-reported frequency of sexual intercourse between the 2 groups. Thakar et al. in London studied 279 women and found that the patients in the SAH group had a shorter hospital stay and a lower rate of fever than those in the TAH group, but they did not report any difference in sexual function in the 2 groups after 1 year [5]. All women in our study were premenopausal and under 50 years old compared with the British trial, which included menopausal and premenopausal women under 60 years old [5]. Ethnic differences among the women in the British survey compared with the homogenous ethnic composition of our group of patients may explain some of the differences in these 2 studies regarding postoperative complications (fever, hospital stay); however there were similar finding about sexual functioning in the 2 studies. Kupperman et al. in the USA studied 135 women and also reported no difference in sexual function between the 2 groups after 2 years [21]. Zobbe et al. in Denmark reported no significant difference at l-year follow-up

\begin{tabular}{|c|c|c|c|c|c|}
\hline \multicolumn{6}{|c|}{$\begin{array}{l}\text { Table } 2 \text { Postoperative events and self-reported changes in dyspareunia and sexual } \\
\text { function changes in women having subtotal hysterectomy or total hysterectomy } \\
\text { at } 6 \text { month follow-up }\end{array}$} \\
\hline \multirow[t]{2}{*}{ Variable } & \multicolumn{2}{|c|}{$\begin{array}{c}\text { Subtotal } \\
\text { hysterectomy } \\
(\boldsymbol{n}=\mathbf{5 0})\end{array}$} & \multicolumn{2}{|c|}{$\begin{array}{c}\text { Total } \\
\text { hysterectomy } \\
(\boldsymbol{n}=100)\end{array}$} & \multirow[t]{2}{*}{$P$-value } \\
\hline & Mean & SD & Mean & SD & \\
\hline Hospital stay (days) & 4.40 & 1.90 & 4.48 & 1.67 & $0.95^{\mathrm{a}}$ \\
\hline \multirow[t]{2}{*}{ Haemoglobin change (g/dL) } & +0.38 & 0.13 & +0.32 & 0.90 & $0.72^{\mathrm{a}}$ \\
\hline & No. & $\%$ & No. & $\%$ & \\
\hline Pyrexia & 12 & 24.0 & 17 & 17.0 & $0.20^{\mathrm{b}}$ \\
\hline \multicolumn{6}{|l|}{ Dyspareuniac } \\
\hline Increased & 3 & 21.4 & 16 & 41.0 & \\
\hline Decreased & 3 & 21.4 & 12 & 30.8 & $0.15^{\mathrm{b}}$ \\
\hline No change & 8 & 57.2 & 11 & 28.3 & \\
\hline \multicolumn{6}{|l|}{ Frequency of sexual intercourse $e^{d}$} \\
\hline Increased & 2 & 4.2 & 5 & 5.6 & \\
\hline Decreased & 19 & 39.6 & 35 & 39.3 & $0.93^{\mathrm{b}}$ \\
\hline No change & 27 & 56.3 & 49 & 55.1 & \\
\hline
\end{tabular}

${ }^{a}$-test; ${ }^{b}$ Chi-squared and Fisher exact test.

${ }^{c}$ Only in women complaining of dyspareunia before the operation $(\mathrm{n}=14$ in subtotal hysterectomy and $\mathrm{n}=39$ in total hysterectomy groups).

${ }^{d}$ Only in women who were sexually active before the operation $(\mathrm{n}=48$ in subtotal hysterectomy group and $\mathrm{n}=89$ in total hysterectomy groups).

$S D=$ standard deviation . 
between women undergoing TAH or SAH in sexual functioning: frequency of desire for sex, frequency of intercourse, frequency of orgasm, quality of orgasm, localization of orgasm or satisfaction with sex life [22]. However, they found that the frequency of dyspareunia decreased significantly 12 months after hysterectomy independent of the operation method. In our study over half the women in both groups reported no difference in levels of dyspareunia before and after the operation and there was no significant difference between groups.
One potential weakness of the present study was the short period of follow-up for assessment of sexual activity and also the subjective assessment of dyspareunia and sexual desire. We suggest a longer period of follow-up in future studies.

In conclusion, the results of this study showed that some clinical complications and the frequency of sexual intercourse were similar following SAH and TAH. Therefore a shift towards SAH seems unwarranted from the point of view of sexual functioning and we suggest TAH as the first choice of hysterectomy as the cervix is also resected and the potential for malignancy is omitted. More extensive studies are still needed in order to determine the optimum type of hysterectomy.

\section{Acknowledgements}

We are indebted to all personnel of the Gynaecology Department and operating room for their help in preparing of the patients. This study was supported financially by Babol Medical University.

\section{References}

1. Jones HW, Rock JA. Telinde's operative gynecology, 9th ed. Philadelphia, Lippincott Williams and Wilkins, 2003:799-827.

2. Berek JS. Novak's gynecology, 13th ed. Philadelphia, Lippincott Williams and Wilkins, 2002:765-7.

3. Ryan KJ et al. Kistner's gynecology and women's health, 7th ed. Philadelphia, Mosby, 1999:137-9.

4. DeCherney AH, Nathan L, eds. Current diagnosis and treatment: obstetrics and gynecology, 9th ed. New York, McGraw Hill, 2003:870-6.

5. Thakar R et al. Outcomes after total versus subtotal abdominal hysterectomy. New England journal of medicine, 2002, 347(17):1318-25.

6. Nathorst-Böös J, Fuchs T, von Schoultz B. Consumer's attitude to hysterectomy. The experience of 678 women. Acta obstetricia et gynecologica scandinavica, 1992, 71:230-4.

7. Manyonda IT et al. The influence of suture material on vaginal vault granulation following abdominal hysterectomy. British journal of obstetrics and gynaecology, 1990, 97:608-12.

8. Kilkku P, Grönroos M. Peroperative electrocoagulation of endocervical mucosa and later carcinoma of the cervical stump. Acta obstetricia et gynecologica scandinavica, 1982, 61:265-7.

9. Hendry WF. Urinary tract injuries during gynaecological surgery. In: Studd J, ed. Progress in obstetrics and gynecology, 5th ed. Edinburgh, Churchill Livingstone, 1985:362-77.

10. Whitelaw JM. Hysterectomy: a medical-legal perspective, 1975 to 1985. American journal of obstetrics and gynecology, 1990, 162:1451-8.

11. Farrell SA, Kieser K. Sexuality after hysterectomy. Obstetrics and gynecology, 2000, 95:1045-51.

12. Lauridsen L, Jensen VC. [Total versus subtotal hysterectomy. A follow-up study]. Ugeskrift for laeger, 1961, 123:298-307 [in Danish].
13. Kilkku P et al. Supravaginal uterine amputation vs hysterectomy. Effects on libido and orgasm. Acta obstetricia et gynecologica scandinavica, 1983, 62:147-52.

14. Munro MG. Supracervical hysterectomy: a time for reappraisal. Obstetrics and gynecology, 1997, 89(1):133-9.

15. Kilkku P. Supravaginal uterine amputation versus hysterectomy with reference to subjective bladder symptoms and incontinence. Acta obstetricia et gynecologica scandinavica, 1985, 64:375-9

16. Kilkku P, Hivonen T, Grönroos M. Supra-vaginal uterine amputation vs. abdominal hysterectomy: the effects on urinary symptoms with special reference to pollakisuria, nocturia and dysuria. Maturitas, 1981, 3:197-204.

17. Kilkku $P$ et al. Supravaginal uterine amputations vs hysterectomy, effect s on libido and orgasm. Acta obstetricia et gynecologica scandinavica, 1983, 62:147-52.

18. Kilkku P. Supravaginal uterine amputation vs. hysterectomy: effects on coital frequency and dysepareunia. Acta obstetricia et gynecologica scandinavica, 1983, 62:141-5.

19. Virtanen HS et al. Effect of abdominal hysterectomy on urinary and sexual symptoms. British journal of urology, 1993, 72:868-72.

20. Lee A et al. A randomized comparison of total or supracervical hysterectomy: surgical complications and clinical outcomes. Obstetrics and gynecology, 2003, 102(3):453-62.

21. Kuppermann $M$ et al. Sexual functioning after total compared with supracervical hysterectomy: a randomized trial. Obstetrics and gynecology, 2005, 105(6):1309-18.

22. Zobbe $V$ et al. Sexuality after total vs. subtotal hysterectomy. Acta obstetricia et gynecologica scandinavica, 2004, 83:191-6. 